\title{
Regional Education Alliance: Innovative Management Mode of Integration of Urban and Rural Education in Chengdu
}

\author{
Lu Huang \\ School of Political Science and Public Administration \\ University of Electronic Science and Technology of China \\ Chengdu, Sichuan Province, China 610000
}

\author{
Yuyan Chen \\ Education Reform and Development Office \\ Chengdu Research Institute of Education Science \\ Chengdu, Sichuan Province, China 610000
}

\begin{abstract}
At present, the professional development between urban and rural teachers in a region is unbalanced, based on this point, a regional education alliance platform is set up in Chengdu for the deep fusion in research and training, and urban and rural teachers in a region are organized for training of diverse methods and designs for the same lesson so as to improve the professional development of the teachers. Based on early researches, this article analyzes the whole course of the diverse methods and design for the same lesson, showing the advantages and disadvantages in the course so as to further promote the teaching mode and improve the professional development of the teachers.
\end{abstract}

Keywords-urban and rural teachers; professional development of teachers; diverse methods and designs for the same lesson

\section{INTRODUCTION}

The diverse methods and designs for the same lesson mode (hereinafter referred to the DMDL mode) is a research topic for deep and further studies on the new course reform, a research object for the new course reform exploration and diverse teaching methods for course contents and also a specific reflection of substantive research contents and "Methods can be found but not fixed for teaching" on the class teaching theory and practice. The regional educational alliance platform in Chengdu takes the research and training integration as one of the key contents for construction, besides, the DMDL mode is just what it needs and it is designed to promote the professional development of urban and rural teachers.

\section{LITERATURE REVIEW}

Tang Jianlan and Huang Liling ${ }^{1}$ summarize the definition of the DMDL, thinking that the DMDL is a teaching and research mode which, based on the different teaching designs but aiming at same teaching topic, is adopted in teaching. The DMDL activities may promote teachers to share experience, unify what they have and teach and use what

1. Tang Jianlan, Huang Liling, "Three- Course Activities" Making the Diverse Methods and Designs for the Same Lesson Work Better [J]. Journal of Teaching and Management, 2012,(07):34-35. they have had. Zhang Lanting ${ }^{2}$ points out that based on such a classroom teaching mode, teachers can learn from and discuss each other so as to get improved together.

The DMDL may be different teaching plans designed by a teacher for the teaching contents or teaching plans designed by several teachers for the same teaching contents or different teaching plans designed by all teaches. Liu Liping ${ }^{3}$ calls the DMDL as a one-teacher or more teachers DMDL. Li Guohua and Wang Lianrong4 summarize and get seven types, namely, question-based DMDL, case-based DMDL, help-based DMDL, display-based DMDL, guest-based DMDL, progress-based DMDL and topic-based DMDL.

As for the DMDL, the key point is to clarify same for difference. Bo Weiying ${ }^{4}$ makes deep consideration, pointing that the same means to analyze textbooks together, watch the teaching effect together; the difference means diversity in teaching, including diverse teaching philosophy, diverse teaching scenario, diverse learning activities, diverse incentives and so on. Zhang Lanting ${ }^{5}$ also distinguishes the same from the difference in text analysis, goal, process and effect.

No doubt, there are some problems existing in the traditional DMDL. Such as what Tang Jianlan and Huang Liling ${ }^{6}$ have pointed out, disvaluing collective wisdom in class preparation, no questions orientation for listening, class evaluation driven by experience and the like. In the opinions of Li Guohua and Zhang Ruifen ${ }^{7}$, the DMDL has so many

\footnotetext{
${ }^{2}$ Zhang Lanting, Multiple Understanding of the Diverse Methods and Designs for the Same Lesson[J]. Journal of Teaching and Management, 2016,(23):24-26.

${ }^{3}$ Liu Liping, Diverse Methods and Designs for the Same Lesson: Ways for Professional Development of Senior High School English Teacher [J]. Theory and Practice of Education, 2015,(24):41-42.

${ }^{4}$ Bo Weiying, Diverse Methods and Designs for the Same Lesson [J]. Journal of Teaching and Management, 2014,(05):23-25.

${ }^{5}$ Zhang Lanting, Multiple Understanding of the Diverse Methods and Designs for the Same Lesson[J]. Journal of Teaching and Management, 2016,(23):24-26

6 Tang Jianlan, Huang Liling, "Three- Course Activities" Making the Diverse Methods and Designs for the Same Lesson Work Better [J]. Journal of Teaching and Management, 2012,(07):34-35.

${ }^{7}$ Li Guohua, Zhang Ruifen, All Kinds of Mistakes of Diverse Methods and
} 
mistakes: going against the course requirements, going too far in diversity, off textbooks, blind in diversity, purse socalled new and diverse without regard to students, look down on exchanges and cooperation, pursue diversity singly, overstress the commonness but ignore personality, value "the same" but disvalue "the difference"; focus on the "difference" in form but not in "content".

In order to solve the problems existing in the DMDL, Pang Shiqing ${ }^{8}$ thinks that we must follow three basic principles, that is, learning, subject and development. The learning principle is to create the difference aiming at the teaching goal, namely setting a goal for learning. The subject principle is to solve how to learn, namely whether to take teachers or students as the subject for learning, the development principle is to carry out efficient class teaching activities so as to promote the students' creativity and imagination.

In conclusion, the DMDL can improve teachers' enthusiasm and expertise in teaching, making the teaching course more intensive. It is not hard to find in current literatures that more DMDL is a new form of teaching research in colleges, which are limited to a certain college. Accordingly the inter-school and inter-regional DMDL will have a profound significance on promoting teachers' expertise and intensive teaching, which worth deep researches and active promotion.

\section{BACKGROUND}

\section{A. Connotation of Regional Educational Alliance}

The core purpose of the establishment and development of the regional education alliance is to promote the "high level balance" of education in Chengdu. With the premise of limited funds and policy support, its core connotation is "interaction", that is, the interactions between the allied areas, allied schools, resources in allied schools, management, teachers, as well as researches and teaching activities.

\section{B. Contents of Regional Educational Alliance}

Two parties in the alliance will make overall arrangement and plan on the ways and methods for efficient education between regions and deepen the exchanges and share the mechanism construction. Share the regions in development plans, key policies drafting and management system construction, promote the management integration; make an overall arrangement of administrators, college cards and teachers for regular communication to integrate the personnel; make an overall arrangement on teachers training, joint regional topic research and so on to integrate researches; make an overall arrangement on the cooperation in application of information resources, interaction of remote teaching and key projects to integrate resources.

Designs for the Same Lesson [J]. Journal of Teaching and Management, 2011,(02):18-19.

${ }^{8}$ Pang Shiqing, Discussion on Diverse Methods and Designs for the Same Lesson form the Little Horse Crosses the River [J]. Journal of Teaching and Management, 2011, (26): 55-56.

\section{ANALYSIS OF URBAN AND RURAL DMDL}

The process of urban and rural DMDL is almost the same as the traditional school base DMDL, namely preparation before class, comparison in class, thinking after class. Yet the there are multiple participants, diverse in participation form, which makes the significance and effect of the DMDL more prominent.

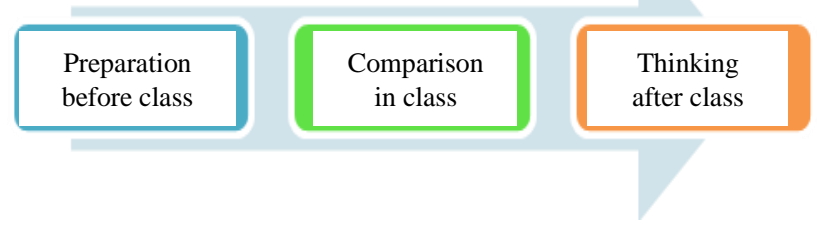

Fig. 1. Process of urban and rural DMDL

\section{A. Preparation before Class}

Lesson preparation is the first step for the DMDL activity, within the past DMDL activities, mostly the teachers will prepare lessons and design the teaching. But now, the urban and rural DMDL bring them chances for mutual communication, learning and brainstorms. For the DMDL is conducted by teachers from different schools, it means that what teachers stand for is not a person and grade but the schools they come from and even the districts (cities) or counties they come from. Teaching and research groups are set in all schools, which consist of famous teachers, young teachers. There is a system established in the group where each shall be responsible for corresponding plates and sections, independent and cooperative, collective wisdoms are gathered for deep and careful class teaching design. Preparation before will fully stir the enthusiasm of urban and rural teachers for independent thinking, cooperation and communication between teaching research groups in urban and rural schools so as to well process the teaching design.

\section{1) Basis for teachers' independent thinking}

Teachers' independent thinking is a base for DMDL or the preparation before class. The independent thinking here shall include not only main teachers who need independent thinking for lesson preparation but also all teachers in the college teaching and research groups, instructors and researches in local districts (cities) or counties, subject experts and so on. The participation of diverse participants will promote members of groups to set active attitudes and concepts and change simple lesson preparation into well prepared teaching design.

\section{2) Essence in collective discussion}

With the independent lesson preparation, teachers will cooperate to prepare lessons in the teaching and research groups, communicate and help with each other, making brainstorming. Based on course contents, learning conditions with main lecturers centered, the group members will work together to study how to introduce courses, break through difficult courses, adopt what teaching methods and means, how to stimulate students interests and so on. The collective 
discussion is sublimation for the teaching design, which not only broadens the thinking perspective of each member, but also enriches the design philosophy and accurate analyzes the learning conditions and teaching goals. With the participation of researches and experts from the districts (cities) or counties, the education theories are integrated to the teaching practice, making the teaching design more scientific.

\section{B. Comparison in Class}

For the urban and rural teachers DMDL is not limited to a school or a region, instead, it is a cross-regional joint teaching and research, thus it forms two forms namely field teaching and research and remote teaching and research. This article is focused on improving the professional development of urban and rural teachers through the cross-regional urban and rural DMDL, so no more discussion will be conducted on the teaching and research form of the DMDL. Now we take the math class "Secrete of Repeat" as an example, which is taught by two teachers from Chenghua District and Dayi County (Chenghua District belongs to the first cycle layer, Dayi County the third cycle layer), so as to analyze three basic points in the class teaching.

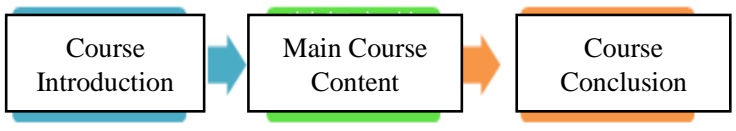

Fig. 2. Comparison in class.

\section{1) Course introduction}

[Teacher from Chenghua District]

$\mathrm{T}$ : (Chat is introduced) (display the chart of lambs in line) what do you find after watching the lambs in line?

$\mathrm{S}$ : (organized, ordered, specify the order)

T: Such organized phenomena are called repeat. The repeat can make the queue ordered, there are more secrets. Today, let's learn together (Introduce the topic: Secrets of Repeat)

\section{[Teacher from Dayi County]}

T: Today, I show you a game, Do you like it? Which two of you want to have a try? Let's find who can remember the most of figures within 10 seconds.

T: Start with ten seconds counted down

$\mathrm{S} 1:$ :००००...

$\mathrm{S} 2: \square \circ \Delta \circ \square \square \Delta$

$\mathrm{T}$ : S1 remembers ( ), S2 remembers ( ).

To S2: You loose, What do you want to say?

$\mathrm{S} 2$ : His figures are regular but mine not

T: You're good at observation and discovery, writing: observation.

T: Find rules through observation. Writing: Rules
T: What are rules? S: Repeat (writing: repeat)

$\mathrm{T}$ : It keeps repeating. Courseware: shows a circle.

This class is designed for grade two students, and scenarios with features of children shall be used to attract the participation of students. Through scenarios, the teachers from Chenghua District will instruct students to observe to get the central contents, namely repeat. Yet through games, the teachers from Dayi County compare two groups of figures in competition so as to get the contents. By contrast, the latter works better to catch what students want, attracting students' attentions through games and getting the contents naturally after competition. The former needs more instruction by teachers and introduce the course through a scenario.

\section{2) Main contents}

\section{[Teachers from Chenghua District]}

1. Observe in order (from disorder to orderly)

T: Each of you should observe in order and show your deskmate the repeated pictures.

S: (talk by and between deskmates for 1-2 minutes).

2. Try to expose the secret

(1) Repeated description through language

Talk by and between deskmates

$\mathrm{T}$ : There are so many repeated pictures, and could you describe how they are repeated? Please select 3 pictures at least, talk to your deskmate the repeat.

Individual report (4-6 students describe by themselves)

(2) Repeatedly show

Show repeatedly independently

T: Just now, when you describe it, it is still not easy to do. Now take pens and papers and use what you like to show the repeat rule (show courseware, lantern figures and learning requirements).

All students report and summarize the methods of show.

$\mathrm{T}$ : (project and discuss and summarize methods to show) How does the student indicate the repeated lanterns? Could you tell us?

S: (report, clearly show use what to indicate big and small lanterns and methods used).

Methods comparison

T: So many methods, Which one do you prefer, Why?

(Through the teacher-student dialogues, teachers show that some methods are easy actually, during the operation, it is suggested to select the simple one to show as possible as we can).

Refine the methods of show show)

(Teacher and students discuss the general methods of 


\section{Apply expansion}

(1) Apply

Students independently show repeats in other pictures.

Guess by the whole class

(2) Expansion

Students talk about repeats in life, watch videos.

Trigger enthusiasm and design works with repeats

[Teacher from Dayi County]

1. Describe rules through language

$\mathrm{T}$ : There are many rules like this in life, let's see, this is a picture of Nair of Mongol (show theme picture)

T: Look at the picture carefully, What rules do you find?

T: What's the repeated part? Could you circle it (show the circle by courseware).

$\mathrm{T}$ : Could you find the rules in other things with the same methods and circle?

\section{Interaction}

(1) Rule indication

Indicate the rules of lanterns arranged

T: You have found so many rules, and could you indicate the rules of lanterns through the method you prefer? Suspend for $3 \mathrm{~s}$. What will you use to indicate big lanterns and small ones?

Indicate methods to indicate symbol and number

Courseware show: $\sqrt{ } \times \sqrt{ } \times \sqrt{ } \times, 12121212$

T: Could you understand the method that I show you?

S: Number and symbol

$\mathrm{T}$ : So many methods are used to indicate rules of lanterns, what's the rule on the earth?

T: Keep repeating... and what's the repeated part? (circle while speaking).

Give apostrophes

$\mathrm{T}$ : Can the rule be drawn completely?

S: No, we cannot.

T: Then, How?

S: Use apostrophes

T: Yet you have to draw two groups at least before using it.

Enlighten thought

$\mathrm{T}$ : Which one do you prefer in the methods, Why?

Summary: What we want is a simple method to show.

Writing: simple.
(2) Indicate rules of other things in arrangement

T: Select a group of regular things and indicate their rules as quickly as you can and circle the repeated.

Teach check and find methods to indicate each rule.

(3) Find characteristics of repeated rules and ratiocinate as per the rules

T: What's the same for the rules (they occur repeatedly).

3. Expansion evaluation and show

(1) Have you seen such repeat in life? Could you give an example?

(2) Courseware shows repeats

During the class teaching, both teachers adopt group discussions and personal display, which occur constantly in the class teaching, where students may touch simple rules while discovering and describing the repeated phenomena or things. The teachers from Chenghua District give more time to students to observe or describe independently or jointly so as to consolidate the students' abilities of generalization. The teacher from Dayi County keeps clear logic and acts as a instructor from observation, description to different ways introduced, through questions, the class teaching go ahead, with the teacher's instruction the students are concentrated on learning in class.

\section{3) Class conclusion}

\section{[Teacher from Chenghua District]}

T: We have got the secrets of repeat through this lesson, and you are expected to do more observation to see the rules.

\section{[Teacher fro Dayi County]}

T: Every one of you is hoped to have smart eyes to find repeats and secrets in life (writing: secrets) Look at the theme figure again, and what have we got today?

There are all kinds of class conclusions, some are summaries of this lesson, some is longing to the next learning and some are expanded to life. No doubt, both the teachers have made summaries and expectation to life at the end of the class.

\section{Thinking after Class}

For the field DMDLr the remote DMDL, the urban and rural teaching and research groups have to conduct collective discussions. First, urban and rural teachers (two) shall make a briefing of the teaching design, thinking and so on, which is a process for teachers' self-reflection, after class, the teachers shall clarify the thinking and make self-questioning and adjustment according to the class conditions, and get enlightened from other teachings.

The next is the reflection of urban and rural teaching and research groups. For the DMDL, the teaching contents and goals will be the same, and the teachers, students and teaching design will be different. Therefore, the after class reflection is not to pursue a better template but to learn each and draw strengths from each other. The collective 
discussion will promote teachers to capture class rules and form professional habits of self reflection and find ways for professional growth.

The last are experts' comments, the experts shall include researchers, subject experts from the two districts as well as researchers and academic leaders in cities. The experts' comments in a large scope are scientific evaluation on the whole teaching process after rational thought rather than simple discussion on courses. Experts will conduct evaluations from implementation of teaching goals, teaching contents process, operation of teaching strategies, students' participation, the penetration of class culture and so on. Their critics are original, their suggestions are enlightening, which make teachers open, clear and enlightened and become theoretical guide for improving the class teaching. As for the lesson evaluation, we have to have double insights as critics and appreciation, we shall not only reflect and evaluate the value of the lessons but also enable the urban and rural teachers who participate to learn how to criticize, appreciate and realize so as to promote the professional development of their own.

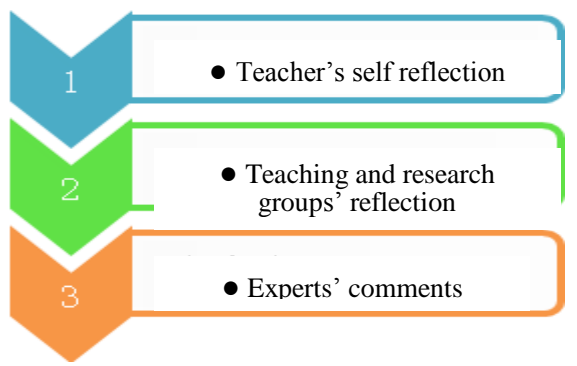

Fig. 3. Flow diagram of thought after class

\section{CONCLUSION}

The DMDL is a new teaching and research mode, which does good to improving the professional development of teachers. In the framework of regional education alliance in Chengdu, achieve the urban and rural DMDL among regions, collect the teaching wisdom for integration so that urban and rural teachers can learn from each other and make progress together. The improvement of professional development of urban and rural teachers can not only make up for the imbalance of regional teachers resources but also to expand the radiation of high quality educational resources, saving educational costs and promoting the urban and rural fair education. It is just done like rather than donating people fish, it is better to teach them to fish.

\section{REFERENCES}

[1] Tang Jianlan, Huang Liling, "Three- Course Activities" Making the Diverse Methods and Designs for the Same Lesson Work Better [J]. Journal of Teaching and Management, 2012,(07):34-35.

[2] Zhang Lanting, Multiple Understanding of the Diverse Methods and Designs for the Same Lesson[J]. Journal of Teaching and Management, 2016,(23):24-26.

[3] Liu Liping, Diverse Methods and Designs for the Same Lesson: Ways for Professional Development of Senior High School English Teacher $[\mathrm{J}]$. Theory and Practice of Education, 2015,(24):41-42.
[4] Li Guohua, Wang Lianrong, All Kinds of Diverse Methods and Designs for the Same Lesson [J]. Journal of Teaching and Management, 2011,(07):34-37.

[5] Bo Weiying, Diverse Methods and Designs for the Same Lesson [J]. Journal of Teaching and Management, 2014,(05):23-25.

[6] Li Guohua, Zhang Ruifen, All Kinds of Mistakes of Diverse Methods and Designs for the Same Lesson [J]. Journal of Teaching and Management, 2011,(02):18-19.

[7] Pang Shiqing, Discussion on Diverse Methods and Designs for the Same Lesson form the Little Horse Crosses the River [J]. Journal of Teaching and Management, 2011, (26): 55-56.. 